\title{
Educação profissional e tecnológica: contribuições da pesquisa para a compreensão da constituição docente
}

\section{Professional and technological education: research contributions to the understanding of the teaching constitution}

Vidica Bianchi (vidica.bianchi@unijui.edu.br)

Universidade Regional do Noroeste do Estado do Rio Grande do Sul-UNIJUí

Adriano Ferreira da Silva Neto (professor.adrianoneto@gmail.com)

Universidade Regional do Noroeste do Estado do Rio Grande do Sul - UNIJUí/UNIBALSAS

Wellington Nascimento Silva (wellns36@gmail.com)

Universidade Regional do Noroeste do Estado do Rio Grande do Sul - UNIJUÍ/UNIBALSAS

Eva Teresinha de Oliveira Boff (evaboff@unijui.edu.br)

Universidade Regional do Noroeste do Estado do Rio Grande do Sul-UNIJUí

Resumo: Este estudo teve por finalidade realizar um levantamento do tipo "estado da arte" de artigos publicados no site de periódicos da Coordenação de Aperfeiçoamento de Profissionais de Ensino Superior (CAPES) entre 2015 a 2019. O objetivo é analisar o processo de constituição do professor, suas adversidades e desafios para atuar na Educação Profissional e Tecnológica (EPT), bem como investigar acerca do que vem sendo publicado em relação a temática currículo e formação de professores no contexto da educação profissional. Trata-se de uma revisão sistemática da literatura, cuja análise teve como base os argumentos de Moraes e Galiazzi (2007) sobre análise textual discursiva (ATD). Foram encontrados 1495 artigos, no entanto, somente 21 se aproximaram dos objetivos deste estudo e dos critérios estabelecidos. Os resultados da pesquisa mostram que a EPT tem se configurado como importante campo de pesquisa, e que existe um crescimento de produções acerca do assunto, no entanto, com poucos escritos no que se refere à constituição do professor da EPT.

Palavras-chave: currículo; constituição dos professores; prática pedagógica

Abstract: This study aimed to carry out a "state of the art" survey of articles published on the website of journals of the Coordination for the Improvement of Higher Education Professionals (CAPES) between 2015 and 2019. The objective is to analyze the process of constitution of the teacher, its adversities and challenges to act in Professional and Technological Education (PTE), as well as to investigate about what has been published in relation to thematic curriculum and teacher training in the context of professional education. It is a systematic review of the literature, whose analysis was based on the arguments of Moraes and Galiazzi (2007) on discursive textual analysis (ATD). In total, 1495 articles were found, however, only 21 approached the objectives of this study and the established criteria. The research results show that PTE has become an important research field, and that there is an increase in productions on the subject, however, with few writings regarding the constitution of the PTE professor.

Keywords: curriculum; constitution of teachers; pedagogical practice.

Recebido em: $27 / 03 / 2020$

Aceito em: 15/09/2020 


\section{INTRODUÇÃO}

As pesquisas sobre o processo constitutivo e a formação de professores da Educação Profissional e Tecnológicas (EPT) publicadas entre 2017 e 2019, tiveram foco na perspectiva da formação docente, na análise do perfil do professor, nas políticas de formação de professores, na constituição histórica da área e nas legislações a ela pertinente.

O Conselho Nacional de Educação, por meio da resolução de n 06/2012 afirma que a formação docente para EPT no nível médio pode ser realizada em cursos em diferentes níveis e como formação continuada (BRASIL, 2012).

Esta resolução, bem como a Lei de Diretrizes e Bases da Educação Nacional (LDB) (BRASIL, 1996), deixa claro em seu texto que a qualificação para o exercício da docência é necessária. Neste sentido, Machado (2008) aponta que há grande necessidade em se criar cursos, de licenciatura para a formação de professores, que sejam capazes de enfrentar os desafios dos profissionais que atuam na área.

Os professores da educação profissional enfrentam novos desafios relacionados às mudanças organizacionais que afetam as relações profissionais, aos efeitos das inovações tecnológicas sobre as atividades de trabalho e culturas profissionais, ao novo papel que os sistemas simbólicos desempenham na estruturação do mundo do trabalho, ao aumento das exigências de qualidade na produção e nos serviços, à exigência de maior atenção à justiça social, às questões éticas e de sustentabilidade ambiental. São novas demandas à construção e reconstrução dos saberes e conhecimentos fundamentais à análise, reflexão e intervenções críticas e criativas na atividade de trabalho (MACHADO, 2008, p. 15).

Para Oliveira e Silva (2018), o docente deve atentar-se à responsabilidade de sua profissão, visando preparar os alunos para os desafios do mundo do trabalho, além de proporcionar uma formação crítica e cidadã. Dessa forma, faz-se necessário que o docente inove frequentemente em suas práticas e aprimore seus conhecimentos pedagógicos, engajando-se no processo de uma formação contínua.

Em 2001, com o objetivo de melhor definir o rumo da formação de professores para a educação profissional, Ribeiro et al. (2011), contribuem com a afirmação de que:

$\mathrm{Na}$ LDB, a proposição é que a formação docente aconteça em cursos de licenciatura, acrescido de, no mínimo, trezentas horas de prática de ensino. Ora, é sabido que as especializações não oferecem estes espaços de prática de ensino e, quando isso acontece, dificilmente esta oferta é de trezentas horas. Mesmo que isso ocorra, ainda há o dispositivo de que a 
especialização situa-se fora do âmbito da graduação, ou seja, não está alinhado com o disposto na legislação (RIBEIRO et al., 2011, p. 108).

Diante do exposto, há que se considerar ainda que nos Institutos Federais a realidade é mais complexa, devido ao fato de que o professor transita por vários níveis, formas e modalidades de ensino simultaneamente. Por isso, a hipótese levantada é de que é mais complexo aos professores da área de formação profissional atender estas demandas, uma vez que grande parte deles são engenheiros, bacharéis ou tecnólogos, sem formação específica no âmbito educacional. Logo, são dotados de um fazer pedagógico que se constrói a partir da experiência profissional específica na área, não vinculada aos conhecimentos pedagógicos sistematizados.

Observa-se que esse cenário é comum na esfera da educação profissional, por isso o reconhecimento da necessidade de superação das políticas de formação docente de caráter pontual e emergencial, a fim de que o professor possa, de fato, compreender as peculiaridades e especificidades da educação profissional. Aproximando-se, assim, da problemática das relações entre educação e trabalho, e estabelecendo, no ato de lecionar, conexões entre as disciplinas e a formação profissional específica.

Compreende-se, a partir destas ideias, que a formação de professores é um processo continuado que contribui para o aperfeiçoamento das práticas docentes, respeitando aos procedimentos metodológicos e objetivando a qualidade do ensino. Neste sentido, a LDB (BRASIL, 1996), em seu Art. 67, trata da experiência docente como pré-requisito para o exercício da profissão de quaisquer outras funções docentes no exercício do magistério. Muitos dos professores de cursos profissionalizantes não são licenciados para o exercício da docência. Isto ocorre devido à grande demanda de mercado, em que o profissional bacharel ganha espaço por estar qualificado, em menos tempo de escolarização, por meio de um curso técnico profissionalizante. Com isso,

a formação de professores torna-se assim, elemento fundamental que constitui para a melhoria da qualidade de ensino, pois implica a aquisição de conhecimento, habilidades e competências que permitem aos professores atuarem no desenvolvimento do ensino, do currículo e da instituição (PIVETTA, p. 18, 2006).

Pivetta (2006) nos chama atenção para o processo da construção do saber, este que ocorre desde a formação inicial e perpassa até a prática educativa do professor, que concretiza, desta maneira, o exercício da docência. Ser professor requer competências e habilidades diferenciadas das demais profissões.

Recebido em: $27 / 03 / 2020$

Aceito em: 15/09/2020 
Assim, a partir de 2005, o estado brasileiro passou a investir em políticas públicas para a ampliação da formação profissional articulada à escola regular, por exemplo, a criação do Programa de Integração da Educação Profissional ao Ensino Médio na Modalidade Educação de Jovens e Adultos-PROEJA (MOURA, 2012) e a criação do Programa Nacional de Acesso ao Ensino Técnico e Emprego (PRONATEC), em 2008, pela rede federal de Educação profissional, Científica e Tecnológica. Deste modo, entre 2003 e 2016, foram construídas 500 novas unidades e estão em funcionamento 644 campi, que cobrem todos os estados brasileiros, oferecendo cursos técnicos, cursos superiores de tecnologia, licenciaturas, mestrados e doutorados. Esta ampliação da oferta de vagas e diversidade de cursos tem exigido a contratação de novos docentes, o que reforça a importância da formação dos professores que ocupam estes novos cargos. De acordo com Tardif (2012),

[...] os saberes pedagógicos apresentam-se com doutrinas ou concepções provenientes de reflexões sobre a prática educativa no sentido amplo do termo, reflexões racionais e normativas que conduzem a sistemas mais ou menos coerentes de representação e de orientação da atividade educativa. (TARDIF, 2012, p. 37)

O exercício da docência impõe ao educador, neste sentido, a seriedade da sua formação, pois, conforme salienta Freire (1997, p. 92) “a incompetência profissional desqualifica a autoridade do professor". Por isso, com a massificação do ensino exercida atualmente, a educação profissional precisa ser mais assistida no sentido de formar professores para atuar na EPT.

Considerando as ideias postas, compreende-se que são muitas as pesquisas e estudos relacionados ao processo de formação de professor da Educação Profissional e Tecnológica (EPT). Mas afinal, cabe questionar: como se constitui um professor da EPT? Como forma de responder a este questionamento, o presente artigo tem o objetivo de analisar o processo de constituição do professor, suas adversidades e desafios para atuar na (EPT), por meio de uma investigação sobre o que vem sendo publicado em relação à temática “currículo, formação de professores e educação profissional”.

\section{PERCURSOS METODOLÓGICOS}

Este artigo apresenta uma revisão bibliográfica, do tipo "estado da arte", sobre o processo de constituição do professor para atuar na Educação Profissional e Tecnológica. Os dados foram obtidos nos artigos presentes no portal de periódicos da 
CAPES $^{1}$, período 2015 a 2019, com os seguintes descritores: currículo and formação de professores and educação profissional; currículo and constituição do professor and educação profissional; currículo and docente da educação profissional. $\mathrm{O}$ quadro 1 indica o número de artigos, com refinamento de acordo com os interesses da pesquisa.

Quadro 01 - Artigos do portal da CAPES, de acordo com os descritores, no período 2015 a 2019.

\begin{tabular}{|l|c|c|c|c|}
\hline Descritores & $\begin{array}{c}\text { Total de } \\
\text { Artigos }\end{array}$ & $\begin{array}{c}\text { Artigos } \\
\text { Revisados/pares }\end{array}$ & $\begin{array}{c}\text { Artigos em } \\
\text { Português }\end{array}$ & $\begin{array}{c}\text { Artigos do } \\
\text { Corpus }\end{array}$ \\
\hline $\begin{array}{l}\text { Currículo AND formação de professores } \\
\text { AND educação profissional. }\end{array}$ & 569 & 429 & 313 & 08 \\
\hline $\begin{array}{l}\text { Currículo AND constituição do professor } \\
\text { AND educação profissional }\end{array}$ & 300 & 219 & 150 & 03 \\
\hline $\begin{array}{l}\text { Currí́culo AND docente da educação } \\
\text { profissional }\end{array}$ & 626 & 498 & 334 & 10 \\
\hline TOTAL & $\mathbf{1 4 9 5}$ & $\mathbf{1 1 4 6}$ & $\mathbf{7 9 7}$ & $\mathbf{2 1}$ \\
\hline
\end{tabular}

Os procedimentos metodológicos utilizados para análise seguem os argumentos da Análise Textual Discursiva (ATD), elaborada por Moraes e Galiazzi (2007, 111). Esta opção metodológica possibilita ao pesquisador vivenciar um "processo integrado de aprender, comunicar e interferir em discursos". A ATD estrutura-se em: unitarização, que é a fragmentação dos textos transcritos em unidades de significado; categorias temáticas, que são as unidades de significado agrupadas segundo suas semelhanças semânticas; comunicação, que são os textos descritivos e interpretativos acerca das categorias temáticas. Os autores que elaboraram a ATD orientam que o primeiro passo de análise é a desconstrução das unidades.

O corpus foi obtido a partir da leitura e análise dos trabalhos selecionados. Os critérios de seleção foram: fizer referência à formação de professores da educação profissional que atuam nas disciplinas técnicas, ou seja, os não licenciados; trabalhos avaliados por pares; trabalhos escritos em língua portuguesa. Logo, foram excluídos os que não se enquadravam nestes quesitos.

Segundo Ferreira (2002), os estudos relativos ao "estado da arte" podem ser definidos como uma modalidade de pesquisa bibliográfica, que têm por objetivo:

O desafio de mapear e de discutir uma certa produção acadêmica em diferentes campos do conhecimento, tentando responder que aspectos e dimensões vêm sendo destacados e privilegiados em diferentes épocas e lugares, de que formas e em que condições têm sido produzidas certas dissertações de mestrado, teses de doutorado, publicações em periódicos e

\footnotetext{
${ }^{1}$ Disponível em www.periodico.capes.gov.br.
}

Recebido em: 27/03/2020

Aceito em: 15/09/2020 
comunicações em anais de congressos e de seminários (FERREIRA, 2002, p. 258).

Segundo Haddad (2002, p. 9), a constituição deste tipo de estudo/pesquisa:

[...] permite, num recorte temporal definido, sistematizar um determinado campo do conhecimento, reconhecer os principais resultados da investigação, identificar temáticas e abordagens dominantes e emergentes, bem como lacunas e campos inexplorados abertos a pesquisas futuras.

A pesquisa bibliográfica no formato de estado da arte, quando bem sistematizada, situa o pesquisador sobre o estado do conhecimento e a perspectiva que é dada a temática investigada. Neste sentido, para investigar sobre como ocorre a formação de professores para atuar nos cursos de EPT, torna-se fundamental para que educadores possam contribuir na constituição destes sujeitos.

\section{RESULTADOS E DISCUSSÃO}

Os argumentos e análises dos escritos encontrados no banco de periódicos da CAPES, foram necessários para a compreensão do conhecimento, a partir de pesquisas já realizadas, no que se refere ao currículo, formação de professores e educação profissional. No período considerado de 2015 a 2019, foi possível mapear trabalhos analisados por pares de grande importância para a sociedade acadêmica.

Conforme os dados apresentados no Quadro 01, foram encontrados um total de 1495 artigos. Após verificar acerca do tipo de avaliação dos trabalhos, que deveria ser por pares, a amostragem foi reduzida o número de 1146 trabalhos. Posteriormente, quando verificados os que estavam em língua portuguesa, o número ficou em 797 artigos. A partir da leitura dos títulos e do resumo, restaram 21 trabalhos para serem explorados e analisados em sua totalidade, visto que somente estes abordavam a educação profissional na perspectiva almejada e atendiam aos critérios estabelecidos.

As pesquisas selecionadas sobre o processo constitutivo e a formação de professores da Educação Profissional e Tecnológicas, publicadas entre 2015 e 2019, tiveram foco na perspectiva da formação docente para EPT, na análise do perfil do professor, nas políticas de formação de professores para a Educação Profissional, na constituição histórica da área e nas legislações a esta pertinente. 
Sobre a legislação, o documento mais recente elaborado, a Base Nacional Comum Curricular-BNCC (BRASIL, 2018), se refere à esta modalidade ao citar a LDB (BRASIL, 1996). O documento salienta que está orientada pelos princípios éticos, políticos e estéticos que visam à formação humana integral e à construção de uma sociedade justa, democrática e inclusiva, como também é fundamentado nas Diretrizes Curriculares Nacionais da Educação Básica (DCN) (BRASIL, 2013), que contemplam a Secretaria de Educação Profissional e Tecnológica. Já sobre a formação de professores para atuar nesta modalidade, especificamente, a BNCC (BRASIL, 2018), não menciona.

Oliveira e Nogueira (2016) discutem sobre as características atuais da Formação de Professores da Educação Profissional, salientando a força contrária por parte da cultura da área e as dificuldades das próprias instituições formadoras na oferta da licenciatura para a EP. Não apenas a cultura dos sujeitos dessas instituições que costumam não valorizar a formação pedagógica para a docência na EP, mas também falta de estudos sobre a denominada epistemologia das áreas técnicas que subsidie a construção de projetos político- pedagógicos para a formação dos seus professores.

Guedes e Sanchez (2017), em seu trabalho, abordaram as perspectivas da docência na EPT, os saberes docentes e as dificuldades que envolvem a formação de professores e as especificidades que envolvem o docente que atua nesta modalidade. Para esta investigação, os autores adotaram uma abordagem teórica sobre a evolução do ensino profissional e das mudanças das leis que asseguram a EPT, obtendo um trabalho que resultou numa análise de dados (falas de docentes) confrontadas com reflexões teóricas. A partir disso, em seu artigo, buscaram investigar como a temática se faz presente em uma instituição que atua nesta modalidade de ensino e como tem influenciado na prática docente. Foi possível, assim, compreender e identificar as concepções sobre a educação profissional, bem como levantar dados com os próprios docentes sobre suas formações, identidades, experiências, práticas, concepções, importância da formação pedagógica para a atuação profissional, dificuldades enfrentadas, entre outras. Conforme afirmam Guedes e Sanchez (2017), os resultados apontam que a formação docente para a educação profissional se pauta na questão de que, atualmente, professores licenciados que trabalham na educação profissional não estão preparados para tal feito, principalmente, por não terem trabalhado em sua 
formação aspectos da relação entre trabalho e educação, tendo, na base de sua formação acadêmica, apenas o ensino médio de caráter propedêutico.

Freitas et al. (2016) abordam os saberes docentes sobre o processo de ensino e de aprendizagem e sua importância para a formação profissional em saúde, destacam a necessidade de se ampliar a discussão acerca do tema, sobretudo no que se refere ao papel da gestão e à formação didático-pedagógica do corpo docente em saúde, essencial para se alcançar a formação preconizada pelas Diretrizes Curriculares Nacionais.

Nestes casos, os saberes destes profissionais resultam das experiências do cotidiano e da interpretação subjetiva de sua validade. É este saber que direciona o professor a decidir por esta ou aquela ação em cada caso específico de sala de aula. Assim, Tardif (2012), ao discorrer sobre os saberes experienciais, afirma que:

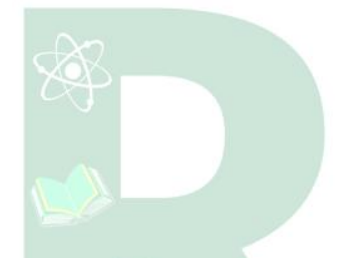

São os saberes que resultam do próprio exercício da atividade profissional dos professores. Esses saberes são produzidos pelos docentes por meio da vivência de situações específicas relacionadas ao espaço da escola e às relações estabelecidas com alunos e colegas de profissão. Nesse sentido, "incorporam-se à experiência individual e coletiva sob a forma de habitus de habilidades, de saber-fazer e de saber ser" (TARDIF, 2012, p. 38).

A pesquisa realizada com egressos de um Curso de Formação de Professores para a Educação Profissional e Tecnológica, feita por Santos e Quadros (2019), indica que estes compreendem as principais dimensões envolvidas na atuação docente e a necessidade de inovação e dinamismo nas aulas. Porém, os autores destacam, pelos relatos obtidos no estudo, "que as práticas destes profissionais continuam a se pautar pela reprodução de procedimentos tradicionais" (p. 38).

Vieira (2018), por sua vez, faz uma análise das políticas de formação de professores para a EPT e identificou, em seu trabalho, que 12 produções dão ênfase a esta temática. Além disso, o autor inventariou as produções acadêmicas acerca do tema em eventos científicos e constatou que no período anterior a 2009, havia pouca produção com o objeto de pesquisa EPT. Esperava-se que com o aumento dos cursos nesta modalidade poderia alavancar a pesquisa na formação docentes para atuar neste tipo de formação.

Souza e Souza (2018) analisaram a formação profissional e o perfil do docente que atua no Instituto Federal do Triângulo Mineiro - Campus Paracatu. O referencial teórico apresentado contemplou diversas concepções teóricas a respeito da formação docente e formação para a EPT. Em sua pesquisa, constataram que, em geral, o docente 
que ingressa na instituição pesquisada possui experiência docente anterior. Além disso, os autores puderam perceber a carência dos docentes quanto à formação. Os resultados, destes autores, revelam que a formação pedagógica se constitui necessária também aos docentes da EPT, uma vez que eles não consideram sua formação inicial como suficiente para a atuação docente.

Oliveira e Silva (2018), no que lhe concernem, realizaram uma investigação de abordagem qualitativa com quatro professores bacharéis de um Campus do Instituto Federal de Goiás que atuam na EPT. Dentre os participantes, dois professores já possuíam experiência em sala de aula, e outros dois professores que haviam iniciado a carreira docente no início do ano 2018. De acordo com os autores, a entrevista favoreceu a captação imediata e corrente das informações desejadas, permitindo inclusive o aprofundamento de pontos levantados por outras técnicas de coletas de análise mais superficial, sendo dividida em duas categorias: o perfil docente e o olhar docente sobre suas práticas pedagógicas. Oliveira e Silva (2018) perceberam, a partir das investigações com os profissionais, a presença de uma prática pedagógica repetitiva apoiada no Plano de Ensino, com requisitos pré-programados, possivelmente sem reflexão pedagógica e/ou contextualização de temáticas, contando apenas com o objetivo de cumprir o cronograma. Além disso, averiguaram que a ministração dos conteúdos ocorre por meio de aulas expositivas, uso de slides e exercícios realizados, na maioria das vezes, de maneira individual pelo estudante; outros, em grupo. No quesito de percepção da aprendizagem, os docentes bacharéis afirmam que conseguem identificar quando o aluno aprende ou não. Quanto à metodologia, todos eles afirmam que criaram suas próprias metodologias de atuação em sala de aula e que estão abertos para obterem outras formas metodológicas.

Silva e Souza (2017), discutem sobre o exercício da docência por bacharéis da engenharia. Analisa os perfis profissionais dos entrevistados por meio da experiência vivida no Instituto Federal de Educação e Tecnologia de João Pessoa na Paraíba. Concluem que os bacharéis tornaram-se professores por uma necessidade ocasionada pelo desemprego, insatisfações com o laboro na empresa privada e por uma estabilidade profissional no setor público, dentre outros motivos. Daí nos perguntamos; como é o fazer pedagógico desses professores? Uma vez que em seus cursos de graduação não tiveram formação pedagógica. 
Cruz (2017), por sua vez, fez uma pesquisa junto a alunos de cursos de licenciatura de três universidades (federal, estadual e privada) e 40 professores no Estado do Rio de Janeiro, com perguntas fechadas e abertas, para levantamento de dados sobre ensino de didática e aprendizagem da docência na formação inicial de professores. $\mathrm{O}$ autor constatou por meio deste estudo que os temas relacionados ao conhecimento do conteúdo, ao conhecimento pedagógico do conteúdo e ao conhecimento curricular (SHULMAN, 2004) são, de algum modo, considerados nas aulas de didática, didática específica, metodologias e encontros de estágios curriculares supervisionados e suas respectivas práticas de ensino. A abordagem destes temas visa favorecer a construção de um aporte de saberes profissionais necessários ao exercício da docência, porém, os participantes deste estudo contestam a escassez de referenciais práticos. A segunda constatação tem a ver com as aulas de didática, que não são assumidas intencionalmente como objeto de estudo durante a formação, no sentido de serem problematizadas as escolhas e razões dos professores responsáveis pelo direcionamento das aulas. Em relação a isto, tende-se a considerar que isso decorre, em grande parte, da cultura profissional docente, que não estimula a desprivatização da prática dos professores (COCHRAN-SMITH, 2012). Tal desprivatização da prática, no sentido de romper com a ideia de ensino como atividade individual e privada do professor, reforçando o seu isolamento e o seu não desvelamento, pode parecer ameaçador. No entanto, coloca-se como estratégia de formação para ambos, professor que forma e aqueles que estão em formação, uma vez que implica problematizar suas crenças e saberes e construir novas ideias, conhecimentos e experiências para trabalhar com a docência. A terceira constatação diz respeito ao papel do formador, que se mostrou como um diferencial, visto que, para muitos, é ele que faz a disciplina valer a pena ou não. A dimensão prática, tão questionada, apareceu no modo como o formador planeja, organiza e propõe as atividades, avalia e relaciona os temas, apesar de não discutir e incentivar o estudo dos fundamentos que sustentam sua prática, isto é, seu saber de ação pedagógica.

Oliveira e Campos (2017), numa temática diferente não menos importante no que se refere a formação de professores para educação profissional em seu trabalho mostra a insatisfação dos envolvidos na pesquisa com a ausência de formação sistemática para sua atuação profissional. O que nos chama atenção nesta análise dos autores é a importância da formação continua dos profissionais em qualquer área de atuação.

Recebido em: $27 / 03 / 2020$

Aceito em: 15/09/2020 
No entanto, Silva (2016) verificou a ausência de políticas contínuas de formação de professores para a EPT. A falta de formação legalmente estabelecida para a docência, produz impactos sobre a construção da sua identidade profissional.

Ferretti (2018) analisa a lei 13.415/2017, em relação aos artigos e parágrafos que trata da educação profissional técnica de nível médio. Seu estudo vislumbra verificar quais concepções permeia, nessa lei, o fomento de políticas para implementação do ensino em tempo integral com a inserção da EPT nesse contexto. O estudo revela o descompromisso das instituições públicas com formação profissional dos jovens que frequentam o ensino médio integrado a educação profissional, ficando vulnerável aos interesses empresariais e não com a visão mais ampla, crítica e autônoma a respeito do trabalho. Aponta que o artigo sobre a educação profissional não inova sobre a formação especifica para atuar em cursos profissionais técnicos, o único ponto que impõe é a titulação.

Medeiros Neta, et al. (2018a), em sua pesquisa designada como "A educação profissional nas leis de diretrizes e bases: pontos e contrapontos", apontam que a educação profissional não foi priorizada em benefício do desenvolvimento social e sim do capital, uma vez que os interesses das empresas privadas e do desenvolvimento econômico se sobressaíram às políticas públicas educacionais. Concluem que a Lei de Diretrizes e Bases - LDB (1996), mantive um modelo dual de escola que tem como princípio a subordinação da educação aos interesses imediatos da sociedade, entendida como mercado de trabalho. Dessa forma, a escola pública não é suficientemente preparatória para igualar condições frente à classe dominante, a qual não dispões de interesse na emancipação dos sujeitos trabalhadores o que aumenta a disparidade de classes sociais numa sociedade ferventemente capitalista.

Medeiros Neta et. al (2018b), em seu estudo intitulado "Organização e estrutura da educação profissional no Brasil: Da reforma Capanema às leis de equivalência" que as Leis Orgânicas do Ensino, mesmo com a pretensão de organização curricular aumentaram o distanciando do acesso ao ensino superior para os egressos do educação profissional. Para superar essas desigualdades surge a lei da equivalência, com o objetivo de "oportunizar a democratização do ensino através da verticalização de estudos também aos egressos da educação profissional” (p. 233). 
Sales e Reis (2019) analisaram pesquisas relacionadas a elaboração de currículos da educação profissional integrado na oferta do Programa de Educação de Jovens e Adultos - PROEJA. Constatam que a concepção de integração do grupo dos gestores e professores da instituição campo de pesquisa, se materializa num currículo integrado com formas e naturezas diferentes. Isso nos leva ao entendimento que os envolvidos têm um conhecimento superficial sobre o conceito de currículo.

Strobel e Almeida (2017) analisam a formação de professores e políticas curriculares na educação superior e destacam que existe manipulação dos órgãos financiadores internacionais com interesses voltados para o mercado capitalista, gerando imposições curriculares que privilegia a pedagogia técnica. Os pesquisadores salientam de forma inconclusiva que estas entidades possuem a plena consciência que o controle sobre o acesso e ao conteúdo constroem a educação em um país, direciona a médio e longo prazo o futuro para que seus próprios interesses sejam concretizados.

Medeiros, Bossle e Bossle (2019), em seu estudo intitulado "A produção do conhecimento sobre a educação física nos currículos dos Institutos Federais de Educação, Ciência e Tecnologia" demonstram um esforço proveniente da literatura no sentido de consolidar como componente curricular a Educação Física nos Institutos Federais, objetivando ressignificar o modo como os conteúdos são desenvolvidos e compreendidos estabelecendo sentido ao que se aprende e como se aprende, além de evidenciar a necessidade de aprofundar, ampliar e socializar de forma significativa os conhecimentos acadêmicos e científicos desenvolvidos.

Sgarbi at al. (2015) ao discutirem sobre a formação do enfermeiro docente do ensino Técnico em Enfermagem e evidenciaram como as questões curriculares têm influenciado para esta formação. Acreditam que a caminhada que o aluno realiza ao longo de sua formação é o resultado tanto de conteúdos estudados quanto de atividades realizadas decorridas do currículo escolar.

Na pesquisa de Libâneo (2015), o ponto nevrálgico é a dissociação e paralelismo entre os dois tipos de conhecimento durante o ato constitutivo na formação profissional de professores, o disciplinar e o pedagógico. Sua pesquisa deixa evidente que os currículos de formação profissional precisam atingir o ápice da qualidade do ensino de forma que possa assegurar aos novos docentes o pleno domínio do conhecimento científico teórico-prático ligados ao fazer pedagógico.

Recebido em: $27 / 03 / 2020$

Aceito em: 15/09/2020 
Lima (2018) provoca uma reflexão a respeito da constituição do currículo e da prática pedagógica do professor, buscando fundamentos para pensar "porque ensino como ensino". Para isso, procurou tecer os fios que conduziram a caminhada profissional dos professores, da formação inicial aos primeiros anos de atuação do magistério, destacando a sala de aula como local capaz de propiciar a aprendizagem da docência. Portanto, pensar sobre a própria atuação profissional, "porque ensino como ensino", exigiu um exercício de reflexão tamanho acerca do efetivo trabalho docente. A partir da produção de cada linha e de cada parágrafo, se revelam aos poucos os traços de uma trajetória constituída de história, de desafios, de medos, de incertezas, e de momentos que precisam ser enaltecidos por expressarem desejo de mudança, superação e aprendizagem contínua. Muitos são os saberes que se necessita para desenvolver o ofício de professor. Assim, o fazer docente se sustenta em conhecimentos científicos, advindos de diferentes fontes, sendo permeado por saberes da ação, que são adquiridos a partir de experiências de trabalho vividas em diferentes espaços no exercício da docência.

Neste sentido, o estudo de Richit e Hupalo (2019) aponta para a

necessidade de valorização e promoção dos processos reflexivos sobre a prática docente, pelos próprios docentes, relacionando teoria à prática no trabalho docente, como forma de promover, também, práticas reflexivas e emancipadoras com os alunos em sala de aula. O professor de Educação Profissional precisa assumir a responsabilidade de seu papel no contexto educacional e levantar questões sobre o que e como ensinar, conhecendo os propósitos e as condições escolares, envolvendo a sociedade na educação de uma classe de intelectuais que rompam com os paradigmas que balizam a melhoria da educação (RICHIT; RUPALO, 2019, p. 47).

Estudos apontam que o professor formador de professores deve trabalhar na perspectiva da racionalidade prática, partindo da análise da prática docente para compreender os mecanismos e dispositivos mobilizados pelo professor durante sua ação profissional, o qual obterá êxito, conforme sua capacidade para conduzir a complexidade existente no processo e resolver problemas práticos, por meio da integração entre conhecimento e técnica. Porém, transitar entre a posição de Bacharel e a posição de professor da Educação Profissional e Tecnológica implica lidar com elementos antes reconhecidos ou pouco alinhados com os conhecimentos desenvolvidos no decorrer da formação inicial (SANTOS; QUADROS, 2019).

Quanto aos percursos metodológicos das produções analisadas, a maioria predominou-se as de abordagens qualitativas do tipo estudo de caso. Salienta-se que 
uma das revistas que foi fonte da pesquisa, a Holos, é uma publicação online do Instituto Federal do Rio Grande do Norte (IFRN), pioneira no seguimento, bem avaliada no qualis da CAPES, e que tem como objetivo publicar artigos que contribuam para os estudos de temas interdisciplinares, visando contribuir para a divulgação de pesquisas sobre a formação de professores para educação profissional e tecnológica.

Considerando os artigos analisados, emerge a categoria Formação Docente na Educação Profissional. Esta categoria apresenta relevância, visto que normalmente os professores desta modalidade de ensino não apresentam formação pedagógica. Portanto, surge a necessidade de aprofundamento sobre tal temática. Neste sentido, a partir de uma discussão sobre Educação Profissional e Tecnológica (EPT) nos Institutos Federais de Educação, Ciência e Tecnologia, considerando a formação dos professores não licenciados que atuam nos cursos de Educação Básica sem a necessária habilitação, conforme preconiza a legislação em vigor, Oliveira e Sales (2015), defendem que "uma educação de qualidade, perpassa, obrigatoriamente, pela formação de seus professores, daí a importância de uma política formativa institucional que abarque as especificidades e singularidades da formação docente nessa modalidade de ensino" (p. 10174). Em complemento a esta ideia, Carvalho e Souza (2014, p. 887) afirmam que:

A necessidade de se avançar para uma epistemologia da formação com bases na concepção de práxis, que propicia a articulação dialética entre a prática social e seus fundamentos teóricos, históricos, econômicos etc., capazes não apenas de compreendê-la, mas também de transformá-la.

A formação do indivíduo não está relacionada somente com os saberes ou conhecimentos formalmente estabelecidos pelas instituições. Pelo contrário, trata-se de um processo amplo e envolve situações que emergem do cotidiano ou do saber não formal. Cabe ao professor a sensibilidade para fazer a interação entre estas dimensões. Neste sentido, Pinto e Fonseca, (2017, p. 65) comentam que

O papel do professor é fundamental neste sentido, por ter como principal motivação conduzir o aluno ao processo pedagógico considerando que este aluno já traz um conjunto de saberes. Cabe ao professor a sensibilidade de utilizar, em meio ao fazer pedagógico em sala de aula, situações e saberes que emergem de experiências de interação social, significação e ressignificação indo além do que foi prescrito.

Para além da formação do professor, outra questão fundamental vem à tona ao se tratar da FPT, a qual diz respeito ao desenvolvimento do currículo nos cursos profissionalizantes. Mais do que em outras modalidades, existe a tendência que o currículo seja desenvolvido segundo a lógica do mercado.

Recebido em: 27/03/2020

Aceito em: 15/09/2020 
Neste aspecto, retoma-se a discussão de currículo, ancorado na teoria crítica e trabalhos de crítica cultural e sociológica, defendida por Apple (2008) como central na educação sobre a qual conhecimento é considerado legítimo. Neste cenário, o papel do professor é intencional e inter-relaciona a autorreflexão e a reflexão social. Por isso,

Nossa tarefa é ensinar e aprender; levar nossas indagações tão a sério quanto o tema requer; e receber as críticas que nos fazem respeitosa e abertamente; desejá-las mesmo, para que também possamos ser convocados a questionar nosso próprio senso comum, da mesma forma que pedimos aos outros (APPLE, 2008, p. 55)

Sacristán (2017, p. 58) discorre que "o currículo define um território prático que pode ser discutido, investigado, mas, acima de tudo, sobre o qual intervir". Assim, a falta de aproximação entre o conhecimento cotidiano e o currículo formal faz com que surjam novas situações e temas, não previstos nem planejados. No caso da EPT, destas situações podem emergir um conjunto de saberes que suscitam significado a este conhecimento.

Ao desenvolveram uma pesquisa para investigar a problematização e reconhecimento de teorias e práticas de professores em formação para o ensino de Ciências, com foco no educar pela pesquisa, Kierepka e Zanon (2019, p. 18) apresentam como resultados que:

\begin{abstract}
A problematização de práticas e teorias pode ser realizada em conjunto pelos professores da escola, constituindo-se a escola em uma comunidade reflexiva. Bem como, a categoria problematização também pode ser norteadora do planejamento das aulas, situando-se a prática em torno da solução de problemas de forma colaborativa, priorizando as interações sociais que se oportunizam em sala de aula. E, para isso, o ensino pode ser orientado pelo Educar pela Pesquisa.
\end{abstract}

Em relação à constituição docente para atuar na EPT, também poder-se-ia valer-se da problematização da prática e teorias, uma vez que estes profissionais se deparam com situações cotidianas que imprimem solução de problemas que necessitam de colaboração e de pesquisa.

\title{
4. CONSIDERAÇÕES FINAIS
}

A partir da análise das produções acadêmicas encontradas na base de periódicos da CAPES, no período de 2015 a 2019, pode-se perceber que os estudos realizados sobre a formação de professores para EPT têm despertado interesse por parte de pesquisadores nacionais. A crescente demanda indica a necessidade de formação de 
professores nesta modalidade de ensino, pois, a partir dela, jovens buscam atalhos para uma colocação no mercado de trabalho com mais rapidez, uma vez que se tratam de cursos técnicos e tecnólogos, com carga horária reduzida em comparação aos cursos de graduação licenciatura e bacharelado.

No tocante aos conteúdos abordados nos trabalhos lidos, percebe-se que boa parte centraliza os estudos "in loco" nos Institutos Federais de Educação Superior (IFES), por serem os maiores ofertantes destes cursos, focando nos saberes docentes e na constitucionalidade da profissão professor, no entanto, pesquisadores ainda destacam os aspectos históricos e legais da EPT. Registra-se, também, que nenhum trabalho mencionou relatos de experiências vividas no percurso de constituição do saber para torna-se um professor. Dos 21 artigos analisados, cinco mencionam a importância da formação continuada dos professores da EPT, porém, abordaram a oferta de cursos de licenciatura para exercício da profissional e tampouco realizaram a análise dos currículos das Instituições de Educação Superior (IES) para a oferta de disciplinas que fomentem uma qualificação da área.

Por fim, este estudo contribuiu para análise do panorama das publicações existentes sobre a formação/constituição do professor para atuar na educação profissional e tecnológica, visto que a área tem se configurado como importante campo de pesquisa por encontrar-se em frequente evolução mercadológica onde requer uma formação "técnica" e, para isso, o profissional bacharel da EPT é inserido no contexto da docência. Ao fim deste trabalho, nota-se que mais pesquisas precisam ser feitas para a compreensão do percurso de constituição do professor para atuar na educação profissional e tecnológica. Assim, que este estudo sirva para impulsionar políticas públicas que auxiliem a formação de professores, e que produções acadêmicas comprovem, de fato, que a constituição do docente da EPT esteja sendo constituída de forma eficiente, de forma a atender aos parâmetros de qualidade que tanto precisa a educação.

\section{REFERÊNCIAS}

APPLE, M. W.; BURAS, K. L. Currículo, poder e lutas educacionais: com a palavra, os subalternos. Porto Alegre: Artmed, 2008.

BRASIL. Lei de Diretrizes e Bases da Educação Nacional. Lei número 9394, 20 de dezembro de 1996. Brasília: Diário Oficial da União, 1996.

Recebido em: $27 / 03 / 2020$

Aceito em: 15/09/2020 
BRASIL. Ministério da Educação. Conselho Nacional de Educação. Resolução CNE/CEB N 6, de 20 de setembro de 2012 que define as Diretrizes Curriculares Nacionais para a Educação Profissional Técnica de Nível Médio. Brasília: MEC, 2012.

BRASIL. Ministério da Educação. Conselho Nacional de Educação. Diretrizes Curriculares Nacionais da Educação Básica. Brasília: MEC; SEB; DICEI, 2013.

BRASIL. Base Nacional Comum Curricular. Brasília: MEC, 2018. Disponível em: http://basenacionalcomum.mec.gov.br/images/BNC C_20dez_site.pdf. Acesso em: 22 de dezembro de 2019.

CARVALHO, O. F. de; SOUZA, F. H. de M. Formação do docente da educação profissional e tecnológica no Brasil: um diálogo com as faculdades de educação e o curso de pedagogia, Educação e Sociedade, Campinas, v. 35, nº. 128, p. 629-982, jul./set., 2014.

CRUZ, G. B. da. Ensino da Didática e Aprendizagem da Docência na Formação Inicial de Professores. Cadernos de Pesquisa, v. 47, n. 166, p. 1166-1195, out./dez. 2017.

COCHRAN-SMITH, M. A tale of two teachers: Learning of teach over time. In: Kappa Delta pi Record, july-sept, 2012. p. 108-122.

FERREIRA, N. S. de A. As pesquisas denominadas "estado da arte". Educação \& Sociedade [online], v. 23, n.79, p. 257-272, 2002.

FERRETTI, C. J. A reforma do ensino médio: Desafios à educação profissional. Holos, V. 4, ano 34, p. 261-271, 2018.

FREIRE, P. Pedagogia da Autonomia: saberes necessários à prática educativa. Rio de Janeiro: Paz e Terra, 1997.

FREITAS, D. A.; SOUZA SANTOS, E. M. de; LIMA, L. V. da S.; MIRANDA, L. N.; VASCONCELOS, E. L. NAGLIATE, P. De C. Saberes docentes sobre processo ensino-aprendizagem e sua importância para a formação profissional em saúde.

Interfase: comunicação saúde educação. 20(57): p. 437- 447, 2016.

GUEDES, I. A. C. SANCHEZ, L. B. A Formação Docente para a Educação Profissional Técnica e sua Influência na Atuação dos Professores do Instituto Federal do Amapá - campus Macapá: um estudo de caso. Holos, ano 33, vol. 07, p. 238-252, out.2017.

HADDAD, S. Juventude e escolarização: uma análise da produção de conhecimentos. Brasília, DF: MEC/ Inep/ Comped, 2002. (Estado do Conhecimento n. 8).

KIEREPKA, J. S. N.; ZANON, L. B. Problematização e reconhecimento de teorias e práticas de professores em formação para o ensino de Ciências com foco no educar pela pesquisa. Revista Insignare Scientia, v. 2, n. 1, 20p., jan./abr. 2019.

LIBÂNEO J. C. Formação de Professores e Didática para Desenvolvimento Humano. Educação \& Realidade, v. 40, n. 2, p. 629-650, 2015.

LIMA, F. J. de. Por que Ensino como Ensino? Contextos e Narrativas da Trajetória de um Professor Formador de Professores. Holos, ano 34, v. 02, p. 259-275, fev.2018.

Recebido em: $27 / 03 / 2020$

Aceito em: 15/09/2020 
MACHADO, L. R. de S. Diferenciais inovadores na formação de professores para a educação profissional. Revista Brasileira de Educação Profissional e Tecnológica, v. 1, n. 1, p. 8-22, 2008.

MEDEIROS NETA (a), O. M.; PEREIRA, M. L.; ROCHA, S. R. ; NASCIMENTO F. L. S. A educação profissional nas leis de diretrizes e bases da educação: Pontos e contrapontos. Holos, v. 04, ano 34, p. 172-189, 2018.

MEDEIROS NETA (b), O. M.; LIMA, E. L.; BARBOSA.; J. K. S. F; NASCIMENTO, F. L. S. Organização e estrutura da educação profissional no Brasil: Da reforma Capanema às leis de equivalência. Holos, v. 04, ano 32, p.223-235, 2018.

MEDEIROS, T. N. ; BOSSLE, C. B. ; BOSSLE, F. A produção do conhecimento sobre a educação física nos currículos dos Institutos Federais de Educação, Ciência e Tecnologia. Holos, v. 05, ano 35, p. 1-20, 2019.

MORAES, R; GALIAZZI, M. C. Análise Textual Discursiva. Ijuí: UNIJUÍ, 2007.

MOURA, D. H. PROEJA: Formação técnica integrada ao Ensino Médio. Ministério da Educação: Brasília, 2006. Recuperado em 10 agosto 2012, de http://portal.mec.gov.br/setec/arquivos/pdf2/boletim_salto16.pdf. Acesso em $10 \mathrm{de}$ junho de 2019.

OLIVEIRA J. A.; SILVA Y. F. O. Perfil e percepções sobre a prática pedagógica do professor bacharel na educação profissional. Holos, ano 34, v. 03, p. 348-366, jul. 2018.

OLIVEIRA, M. M de G. W.; CAMPOS, de S. Formação para o apoio matricial: Percepção dos profissionais sobre processos de formação. Revista Saúde Coletiva. v. 27. n .2, 187-206, 2017.

OLIVEIRA, M. R. N. S; NOGUEIRA, C. G. A formação de professores para a educação profissional e o plano nacional de educação (PNE): quais as perspectivas? Holos, Ano 32, Vol. 6, p. 145-155, 2016.

OLIVEIRA R.; SALES, M. A formação docente na educação profissional E Tecnológica: Provocações e Dilemas. Anais... CONGRESSO NACIONAL DE EDUCAÇÃO - EDUCERE, XII, 2015.

PINTO, F. de C.; FONSECA, L. E. G. O currículo oculto e sua importância na formação cognitiva e social do aluno. Projeção e Docência, ano 01, v. 8, n. 1, p. 59-66, 2017.

PIVETTA, H. M. F. Concepções de formação e docência dos professores do curso de fisioterapia do Centro Universitário Franciscano. Dissertação de mestrado, Universidade de Santa Maria, Santa Maria, RS, Brasil, 2006.

RIBEIRO, J. A. R. et al. Questões que permeiam a formação de professores na educação profissional técnica de nível médio. Revista Teoria e Prática da Educação, v. 14, n. 3, p. 97-110, set./dez. 2011.

RICHIT, A; HUPALO, L. Formação de professores na Educação Profissional: uma análise sobre a dimensão pedagógica. Conjectura: Filosofia e Educação, v. 24, p. 27 $56,2019$.

Recebido em: $27 / 03 / 2020$

Aceito em: 15/09/2020 
SALES, M. C.; REIS, R. H. Perspectivas de Integração do Currículo da Educação Profissional à EJA. Revista Espaço do Currículo, v.12, n. 1, p. 153-170, 2019 2019.

SILVA, S. H. S. C.; SOUZA F. C. S. Bacharéis que se tornam professores: inserção e prática profissionais de engenheiros no ensino superior. Holos, v. 05, ano 33, p. 197$213,2017$.

SILVA, F. Plano nacional de educação e seus desdobramentos sobre as novas diretrizes para a formação de professores da educação profissional: identidades profissionais em construção. Holos, 2016, Vol.32, ano 6, p.156-177. 2016

SGARBI, A. K. G. ; MARQUES, M. P. da S. ; CALÇAS, I. R. R. ; MISSIO, L. Formação do enfermeiro para a docência no ensino técnico em enfermagem. Interfaces da Educação. v.6, n.17, p.44-65, 2015.

SHULMAN, L. S. Research on teaching: a historical and personal perspective. In: SHULMAN, L. S. The wisdom of practice: essays on teaching learning, and learning to teach. San Francisco: Jossey-Bass, 2004. p. 364-381.

SOUZA, T. R. A.; SOUZA, J. F. Formação profissional e perfil docente da educação profissional e tecnológica: um estudo no IFTM - Campus Paracatu. Holos, v. 3, ano 34, p. 303-3014, 2018.

SACRISTÁN, G. J. El currículum como estudio del contenido de la enseñanza. In. SACRISTÁN, G. J. et al. Ensayos sobre el currículum: Teoría e Prática. São Paulo: Cortez: Ediciones Morata, Madrid, p.29-62, 2017.

SANTOS, C. B. C. DOS; QUADROS, C. Formação docente e reprodução de práticas: Percepções de Egressos de um Curso de Formação de Professores para a Educação Profissional e Tecnológica. Contexto e Educação, ano 34, n. 107, jan./abr. 2019.

STROBEL NETO, W. ; ALMEIDA, M. de L. P. de. Formação de professores e políticas curriculares na educação superior: Um debate sobre a delimitação do campo de conhecimento. Holos, v. 1, ano 33, p. 91-103, 2017.

TARDIF, M. Saberes Docentes e Formação Profissional. Petrópolis, RJ: Vozes. 2012.

VIEIRA, M. M. M. Formação de Professores da Educação Profissional: Análise de Produções Acadêmicas, Holos, ano 34, v. 02, p. 243-258, fev. 2018. 